\title{
Extinction of an avoidance response using response prevention (flooding) in the guinea pig*
}

\author{
MORRIE BAUM and JOCELYN A. HIGGINS \\ Bishop's University, Lennoxville, P.Q., Canada
}

Thirty-six female guinea pigs were trained to avoid shock in a one-way Miller-type avoidance box and then were given conventional extinction trials with the shocker disconnected. Just prior to extinction, the animals were divided into three different groups and were given either no treatment (immediate extinction), flooding (response prevention) for $15 \mathrm{~min}$, or a $15-\mathrm{min}$ period in a neutral situation. (Flooding consisted of thwarting the avoidance response while forcing the guinea pig to remain in the fear compartment of the Miller box). The results paralleled those obtained with rats in that flooding led to more rapid extinction of the avoidance response than did the other manipulations.

Flooding or response prevention is a behavioral technique which consists of thwarting an avoidance response while forcing the organism to confront the feared stimuli which it previously fled. The flooding procedure can often be effective in leading to the cessation of the flight behavior; that is, flooding leads to subsequent rapid extinction of the avoidance response. A previous paper (Baum, 1970) has reviewed parameters which influence the efficacy of flooding and manipulations which make the procedure more effective in hastening extinction. Since the problem of extinguishing avoidance behavior in animals is to some extent analagous to the removal of phobias in man via behavior therapy, flooding has attracted both clinical and experimental interest (e.g. Boulougouris \& Marks, 1969; Baum \& Poser, in press).

While the flooding technique is receiving increasing attention, one fault of previous research has been the lack of a comparative approach. Most experimental investigations have consisted of either clinical studies in man or experimental studies using rats as Ss, although one early investigation of flooding or response prevention did study dogs (Solomon, Kamin, \& Wynne, 1953). Furthermore, there is a need for experimental replications of phenomena rather than a simple demonstration of an effect. The present study sought to determine if flooding would be effective in hastening the extinction of a simple avoidance response in guinea pigs. The design of this study basically parallels that of a previous investigation (Baum, 1966) which demonstrated that flooding was effective in rats.

* This research was supported by a grant to Morrie Baum from the National Research Council of Canada and by funds from the Bishop's University Committee on Graduate Studies and Research.

\section{SUBJECTS}

The Ss were 36 female guinea pigs obtained from the Canadian Breeding Farm and Laboratories, St. Constant, Quebec, Canada. They were housed in group cages (four per cage) and were maintained on ad lib water and guinea pig chow. At the time the animals were used in the experiment, they weighed $230-385 \mathrm{~g}$.

\section{APPARATUS}

A one-way avoidance box of the type used by Miller (1948) served as the apparatus. The box had no ceiling and was constructed of unpainted piywood. Overall, it measured $23^{1 / 4}$ in. long $x 9$ in. wide $x 9$ in. high (i.d.) and was divided into two equal-sized compartments by a sliding guillotine door. One of the compartments, the "danger" side, had a grid floor consisting of 1/8-in.-diam stainless steel grid bars set at $3 / 4$-in. intervals. The other compartment, the "safe" side, had a plywood floor. The grid floor of the danger compartment was wired so that a scrambled $2.0 \cdot \mathrm{mA}$ electric shock could be administered from a commercially made Grason-Stadler shock source. PROCEDURE

All 36 of the animals underwent the same initial avoidance training procedure. Each $\mathbf{S}$ was placed on the grid floor of the danger compartment in a standard start location facing away from the safe compartment. Simultaneously with placing the animal, the guillotine door was raised, providing access to the safe compartment. If the $\mathbf{S}$ had not crossed completely into the safe compartment within $10 \mathrm{sec}$ of the raising of the guillotine door, then the shock automatically came on and remained on until the animal escaped into the safe compartment. The shock could be avoided entirely if the animal crossed into the safe compartment in less than $10 \mathrm{sec}$. Immediately after the escape or avoidance response, the guillotine door was lowered behind the guinea pig to prevent retracing. The animal was allowed to remain in the safe compartment for $30 \mathrm{sec}$, the fixed intertrial interval, after which it was manually removed and placed into the danger compartment for the next trial. All guinea pigs were trained until they attained an acquisition criterion of 10 consecutive avoidance responses (i.e., 10 consecutive responses with latencies of less than $10 \mathrm{sec}$ ).

After attaining the acquisition criterion, the shocker was disconnected and the guinea pigs were assigned to one of three groups, each having $\mathrm{N}=12$. For a control group, Group C, extinction began immediately upon completion of the 10th consecutive avoidance response. Extinction consisted simply of disconnecting the shocker so that no shocks could be administered, with the trials continuing exactly as before in all other respects. Extinction testing proceeded until the guinea pig ceased fleeing the danger compartment (the extinction criterion being 5 consecutive minutes in the danger compartment without a response) or until 35 extinction responses had been made.

For the flooding group, Group F, a 15-min time delay elapsed between the last acquisition trial and the first extinction trial. During these $15 \mathrm{~min}$, the Ss in Group F were forcibly confined on the grid floor of the danger compartment, with the guillotine door being in the down position to prevent any response. Thus, the animals in Group $\mathrm{F}$ were exposed to the grid floor and cues of the danger compartment (the effective fear CS) for $15 \mathrm{~min}$ while the previous flight response was thwarted. After the 15-min flooding period, the animal was briefly removed from the apparatus for $10 \mathrm{sec}$, following which extinction was given, as for Group C. For a third time-control group, Group TC, a 15-min time delay also elapsed between acquisition and extinction. However, this period was spent in a neutral situation (a plastic pail) and not in the feared compartment. Thus, in comparing Groups $F$ and $T C$, any change in resistance to extinction induced by flooding could not be attributed merely to the element of a time delay which is inherent in the flooding procedure.

Table 1 summarizes the resuits of the experiment, indicating the rate of initial acquisition of the avoidance response and also its extinction. As seen in the table, acquisition was similar for all three groups, as measured by number of shocks 
Table 1

Summary of the Results of the Experiment*

\begin{tabular}{lcccc}
\hline & $\begin{array}{c}\text { Group C } \\
(\mathrm{N}=12)\end{array}$ & $\begin{array}{c}\text { Group F } \\
(\mathrm{N}=12)\end{array}$ & $\begin{array}{c}\text { Group TC } \\
(\mathrm{N}=12)\end{array}$ & $\begin{array}{r}\text { Kruskal- } \\
\text { Wallis H }\end{array}$ \\
\hline $\begin{array}{l}\text { Mean number of shocks } \\
\text { received in acquisition }\end{array}$ & $\mathbf{8 . 0}$ & $\mathbf{1 0 . 6}$ & $\mathbf{8 . 9}$ & $\mathrm{p}>.10$ \\
$\begin{array}{l}\text { Mean number of trials required to } \\
\text { attain the acquisition criterion }\end{array}$ & 25.0 & 26.2 & 27.3 & $\mathrm{p}>.10$ \\
$\begin{array}{l}\text { Mean number of responses } \\
\text { made in extinction }\end{array}$ & $\mathbf{1 6 . 8}$ & 3.6 & $\mathbf{9 . 0}$ & $\begin{array}{l}\mathrm{H}=1023 \\
\mathbf{p}<.01\end{array}$ \\
\hline
\end{tabular}

*All groups received identical avoidance acquisition and then different procedures prior to extinction. Group $C$, a control group, received immediate extinction. Group $F$, the flooding group, received $15 \mathrm{~min}$ of flooding following acquisition and prior to extinction. Group TC, the time-control group, spent $15 \mathrm{~min}$ in a neutral situation following acquisition and prior to extinction.

received and total number of acquisition trials required. The number of responses made in extinction was significantly affected by the various preextinction treatments. In comparing two groups at a time by means of the Mann-Whitney $U$ test, the flooding group, Group F, made significantly fewer responses than the control groups (vs Group TC, $U=29$, $\mathrm{p}<.02$, two-tailed; vs Group C, $\mathrm{U}=21, \quad \mathrm{p}<.02$, two-tailed). The straight extinction and time-control groups (Groups $C$ and TC) did not differ significantly from each other.

Thus, in short, guinea pigs which received a $15-\mathrm{min}$ period of flooding prior to extinction extinguished more rapidly than the no-flooding groups. The effects of flooding could not be simply attributed to the time delay between acquisition and extinction, as this was controlled for.

\section{DISCUSSION}

The present study has demonstrated that flooding or response prevention is effective in hastening the extinction of avoidance responding in the guinea pig. Thus, the technique can be applied successfully in various species. This study paralleled in both procedure and results a previous study which demonstrated the efficacy of flooding in rats (Baum, 1966). Parameters were altered to adjust for the difference in species. Thus, shock intensity was set at $2.0 \mathrm{~mA}$ for guinea pigs in this study and flooding duration was $15 \mathrm{~min}$. (Previous research with rats has shown that these parameters are critical in determining the success of flooding). Using these values, flooding was observed to be effective in guinea pigs.

Further research is needed to determine to what extent knowledge obtained in the study of flooding in rats can be applied to guinea pigs. As well as a fuller exposition of the parameters for guinea pigs, what is also required is a theoretical analysis of flooding in guinea pigs. Is the mechanism by which flooding acts the same in guinea pigs and rats? For example, Baum and his associates (Baum, 1970; Baum \& Gordon, 1970) have stressed the importance of the rats' spontaneous activity during the flooding experience. This activity can be classified into four categories: abortive attempts to avoid, freezing, grooming, or general activity. Furthermore, the incidence of nonfear activity (grooming and general exploratory activity) correlates positively with the success of flooding. The question arises as to whether this correlation also obtains in the case of flooding in guinea pigs. Since species differences make it appropriate to use different sets of apparatus and parameter values for guinea pigs than for rats, observed differences in spontaneous behavior during flooding may be due to (1) the species difference, (2) the apparatus difference, (3) the difference in the parameters employed, or (4) some complex interaction of the above. Much additional research with guinea pigs is required to elucidate these factors and to determine if the correlation between spontaneous behavior in flooding and the efficacy of flooding obtains in guinea pigs, as we have shown in this laboratorv to be the case for rats. Casual observation of the behavior of the guinea pigs during flooding in this study suggests that new categories of behavior are required, since guinea pigs showed virtually no evidence of abortive attempts to avoid or of grooming during flooding. Apart from the comparative aspect of the study, this experiment also replicates the previously observed effect of response prevention or flooding, namely, that it leads to subsequent rapid extinction of the avoidance response.

\section{REFERENCES}

BAUM, M. Rapid extinction of an avoidance response following a period of response prevention in the avoidance apparatus Psychological Reports, 1966, 18, 59-64. BAUM, M. Extinction of avoidance responding through response prevention (flooding). Psychological Bulletin, 1970, 74, 276-284.

BAUM, M., \& GORDON, A. Effect of a loud buzzer applied during response prevention (flooding) in rats. Behavior Research \& Therapy, 1970, 8, 287-292.

BAUM, M., \& POSER, E. G. Comparison of flooding procedures in animals and man. Behavior Research \& Therapy, in press.

BOULOUGOURIS, J. C., MARKS, I. M. Implosion (flooding)-A new treatment for phobias. British Medical Joumal, $1969,2,721-723$.

MILLER N. E. Studies of fear as an acquirable drive: I. Fear as motivation and fear-reduction as reinforcement in the learning of new responses. Journal of Experimental Psychology, 1948, 38, 89-101.

SOLOMON, R. L., KAMIN, L. J., \& WYNNE, L. C. Traumatic avoidance leaming: The outcomes of several extinction procedures with dogs. Journal of Abnormal \& Social Psychology, 1953, 48, 291-302. 